\title{
A CASE OF VASCULAR HAMARTOMA OF NECK IN 8 YEAR OLD BOY
}

B. V. Sreedevi ${ }^{1}$, A. Sasivannan ${ }^{2}$

\section{HOW TO CITE THIS ARTICLE:}

B. V. Sreedevi, A. Sasivannan. "A Case of Vascular Hamartoma of Neck in 8 Year old Boy". Journal of Evolution of Medical and Dental Sciences 2014; Vol. 3, Issue 12, March 24; Page: 3081-3086,

DOI: $10.14260 /$ jemds/2014/2247

ABSTRACT: HAMARTOMA: (From Greek Hamartion: bodily effect) is considered a developmental error. Hamartoma ${ }^{1}$ are not true tumors but represent an over growth of one or more cell types that are normal constituents, but arranged in an irregular fashion of the organ in which they arise, and can occur at a number of sites, and they have been described in many organs. They can occur in the chest, breast, skin, brain, lungs, eye, colon, liver, and uterus. Majority of benign Vascular Tumors are malformations or hamartomas. However, there is no clear cut distinction between Vascular Hamartomas and true benign tumors and are often described together. In this case presentation the boy of 8 yrs. presented with a swelling of 3 months duration in the posterior aspect of neck where a decisive clinical diagnosis could not be arrived even with investigations, but on excision with histopathological report, it had been reported as vascular hamartoma.

KEYWORDS: Hamartoma, Hemangioma, Glomus Tumor, Lymphangioma Circumscriptum, Cavernous Lymphangioma.

CASE PRESENTATION: This young male patient of age 8 yrs. reported to the hospital with swelling on the left side of neck. According to his mother, the swelling was noticed first on the posterior aspect of neck 3 months back which was very small in size but progressively grew to attain the size of $5 \mathrm{~cm}$ swelling. Very occasionally the patient complained of pain over the swelling, other than pain, there was no specific complaint. There was no history of trauma, or any previous surgery. The patient was born to non-consanguineous parents. On examination, the swelling was $5 \mathrm{~cm} \mathrm{X} \mathrm{4cm} \mathrm{in} \mathrm{dimension}$ underneath the cervical fascia and partly under the left sternocleidomastoid muscle. The swelling was soft in consistency, non-compressible, non transilluminant. FNAC from the swelling came as lymph cyst. CT neck showed moderate sized multiloculated lesion in left posterior triangle with minimal hemorrhage visualized in few of the lobulations. There was no obvious deeper extension of the lesion and no enhancement noted on post contrast scans. CT scan reported as lymphangioma. The patient's lesion was explained to his parents and surgical excision was planned. Under general anesthesia, with proper positioning of the neck, with neck turned to the opposite side, a transverse skin crease incision was made and swelling was excised en mass after careful dissection with utmost care. After proper hemostasis skin was approximated and the post-operative period was eventful and patient was discharged on $3^{\text {rd }}$ post-operative day. To our surprise the histopathological result was vascular hamartoma. 


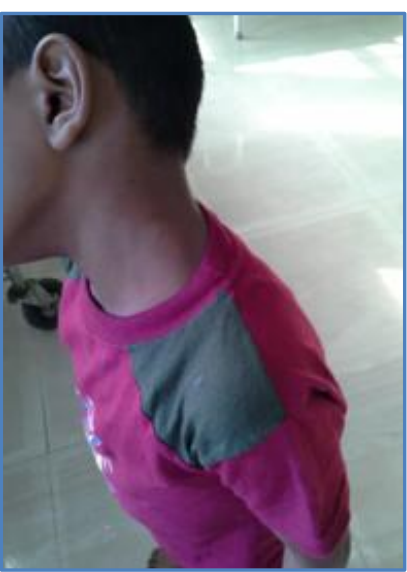

\section{This boy presented with vascular Hamartoma} on the posterior aspect of the neck

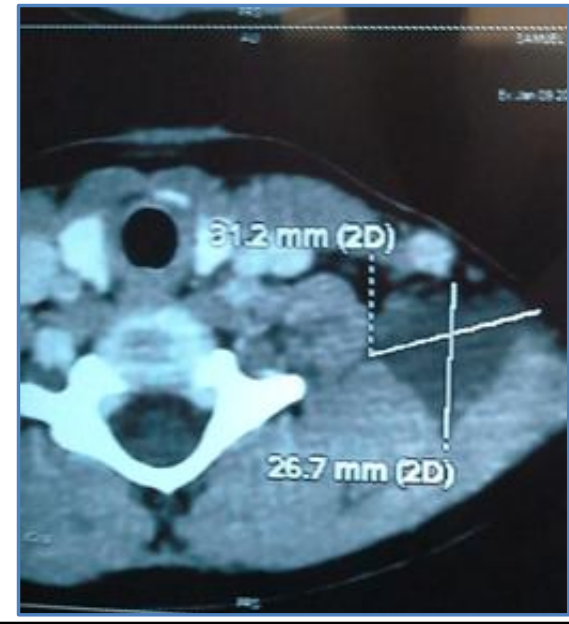

CT Contrast showing the lesion

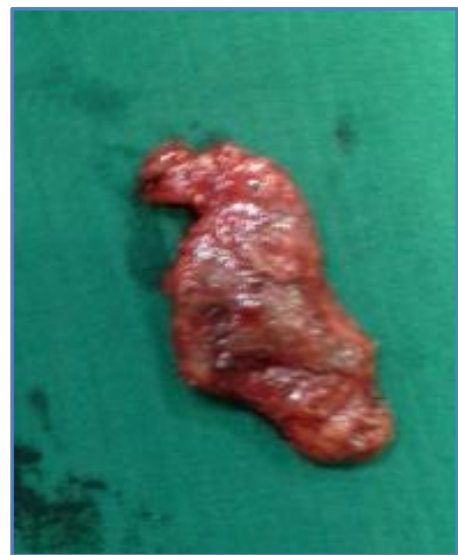

Surgical specimen of the patient
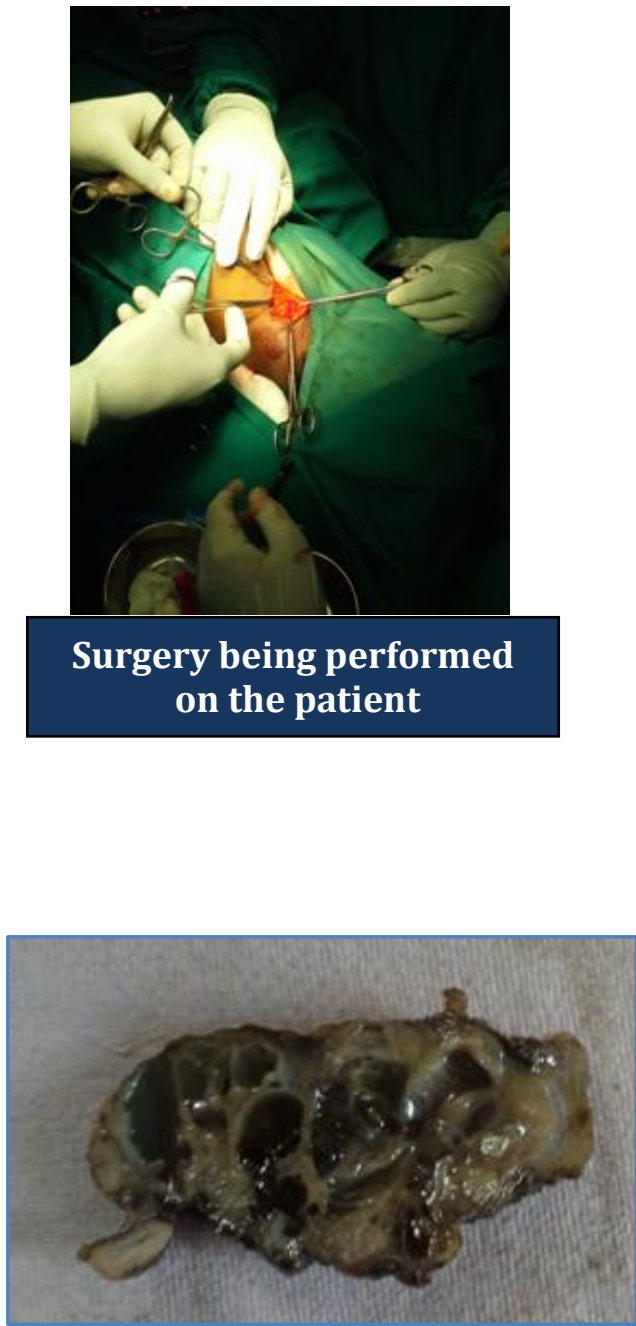

Cut section of the specimen 


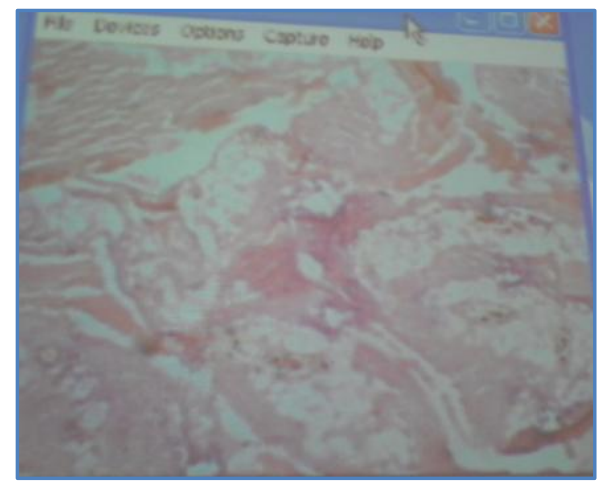

\section{Histo Pathological slide of Vascular}

INTRODUCTION: Hamartomas are lesions which represent focal, benign, overgrowth of a one or more of the mature cellular elements of a normal tissue often with one element predominating. ${ }^{2}$ Although the cells of a hamartoma are often arranged in a highly irregular fashion the distinction between the developmental abnormality and a true benign neoplasm is often conjectural.

DISCUSSION: The literature describes several hamartomas which include hemangiomas, lymphangiomas, Glomus tumor, AV Malformation, Rhabdomyomas, developmental epithelial cysts, 3lipomas, neurofibromas, ${ }^{1}$ Peuz -Jueghers Polyp of the bowel, polyp of the large bowel, bronchial hamartomas, melanocytic, naevi, neurofibromas, in Von reckling hausens disease, bony hamartoma, hamartomas of the hypothalamus. Here, we proceed to the discussion about vascular hamartomas.

HAEMANGIOMA: Are quite common lesions especially in infancy and childhood. Hemangiomas have an estimated incidence of $1 \%$ to $3 \%{ }^{4}$ in white neonates and $10 \%$ to $12 \%$ in children by 1 year of age, occurring with a threefold female preponderance. A lower incidence is reported in dark skinned and Japanese infants. Hemangiomas usually arise sporadically but a family history is reported in approximately $10 \%$ of patients. A small, relatively recent study reported an autosomal dominant inheritance pattern in several family members for both hemangiomas and vascular malformations. Hemangiomas are classified into congenital hemangiomas and hemangiomas of infancy. Congenital hemangiomas can be further sub grouped into RICH's (Rapidly involuting congenital hemangioma) NICH's (Non-Involuting congenital hemangiomas.

HAEMANGIOMAS OF INFANCY: Appear at the age of 1-3 wks. is noted to have a red mark. This increases rapidly for some weeks or even up to 3months until the typical strawberry or raspberry like swelling is present. Based on anatomical depth they are categorized ${ }^{4}$ as superficial (50-60\%) deep (15\%) or combined (25\% to 35\%).Most hemangiomas undergo some degree of involution. This occurs in $50 \%$ of the lesion by age 5 and in $70 \%$ by age 7.0 ther lesion may continue to regress until ages 9 to 10. Unlike hemangiomas of infancy congenital hemangiomas present at birth as fully grown lesions and do not undergo additional post natal growth. Based on the analysis of X chromosome inactivation patterns, some authors have proposed that infantile hemangiomas are the result of the clonal proliferation of endothelial cells. Angiogenesis stimulators such as vascular endothelial growth 


\section{CASE REPORT}

factor (VEGF), basic fibroblast growth factor, monocyte chemo attractor protein -1 and insulin like growth factor 2 are up regulated in all proliferating hemangiomas.

In contrast, the angiogenesis inhibitor metallo proteinase -1 and genes induced by interferon were found to be increased in involuting hemangiomas. These hemangiomas are immune positive for biologic markers. GLUTI, FCYRII, Merosin and Lewis y antigen.

CLINICAL FEATURES: These lesions clinically present as capillary hemangiomas where small or large flat or straightly elevated, red to purple, soft and lobulated lesions, varying in size from a few millimeters to few centimeters in diameter occur. ${ }^{5}$ Strawberry birth marks and portwine mark are good examples. Common sites are skin, subcutaneous tissue, and mucous membrane of oral cavity and lips and they regress spontaneously. When the lesions are cavernous hemangiomas they occur as single or multiple lesions, discrete or diffuse, red or blue, soft and spongy masses. They are often 1$2 \mathrm{~cm}$ in diameter. They are found in deep Dermis, or subcutaneous tissue and may be associated with overlying capillary hemangiomas ${ }^{6}$. They are most common in skin of face and neck, they rarely involutes spontaneously. Though most hemangiomas do not cause many symptoms, rapidly growing lesions can cause a wide variety of complications, including ulceration, infection, hemorrhage, necrosis, airway obstruction, loss of vision and cardiac failure.

INVESTIGATION AND DIAGNOSIS: With the increasing use of pre natal screening, congenital hemangiomas have been detected as early as $12^{\text {th }}$ week of gestation. These tumors initially exhibit fast flow pattern by US and MRI. US with color flow Doppler can be extremely useful in differentiating hemangiomas from similarly appearing vascular malformations that have diminished to absent flow characteristics such as lymphatic malformations. CT scan can delineate the extent and involvement of the hemangiomas and can also be useful in differentiating hemangiomas from lymphatic anomalies. MRI and MRA are useful to know about the extent of involvement with tissue planes and rheological characteristics.

MANAGEMENT: Management includes topical application of corticosteroid cream, Imiquimod 5\% cream, and taking oral and intra lesional corticosteroids. Vincristine and interferon can also be used with variable results.

LASER THERAPY: The pulsed dye laser has been used for treating cutaneous hemangiomas. Based on principles of selective photo thermolysis, this laser putatively arrests the development of hemangiomas and induces their remission, sparing the adjuvant and surrounding cutaneous structures and chromophobes. Surgical excision is undertaken when the lesion poses complications or failure to respond to conservative treatment or becomes an emotional burden to child and family.

\section{Lymphangioma:}

Like hemangiomas, lymphangioma consists of abnormal vessel producing cystic spaces of variable size, lined with a single layer of endothelium. The classification of lymphangioma is complex 1.

They are:

1. Cystic(cystic hygroma) or cavernous lymophangioma

2. Solid 


\section{CASE REPORT}

3. Mixed vascular and lymphatic hamartoma (lymph hemangiomas)

4. Cutaneous (lymphangioma circumscriptum)

Lymphangiomas are dilated dermal lymphatics that blister on to the surface. The fluid is usually clear but may be blood strained. In the long term, lymphangiomas ${ }^{7}$ thrombose and fibrose, forming hard nodules that may raise concerns about malignancy. If lymphangiomas are $<5 \mathrm{~cm}$ across they are termed lymphangiomas circumscriptum and if they are more wide spread, they are termed lymphangiomas diffuse. If they form a reticulate pattern of ridges than it has been termed lymphedema ab igne.

Cystic hygroma presents at birth as a soft, fluctuant swelling in the supra clavicular area, which brilliantly transilluminates, the overlying skin is normal. Regression is the rule by the time the child is 4 yrs. old and surgery is avoided until then. Excision should be undertaken only by specialist. Solid or diffuse lymphangiomas and lymph hemangiomas occur throughout the body and may be associated with tissue over growth Because of the diffuse nature of the lesion complete surgical excision is difficult and local recurrence is common.

Cutaneous lymphangioma or Lymphangiomas circumscriptum consists of multiple cluster of small skin colored vesicles on skin or mucous membranes, classically described as resembling frog spawn. 8 They usually develop in childhood. Point diathermy may control symptoms such as bleeding Excision may be necessary but difficult due to the extent and type of lesion which consists of inter connecting reservoirs of fluid which reconstitute after incomplete excision.

Lymphangiomas frequently weep ${ }^{7}$ (Lymphorrhea, chylorrhea) causing skin maceration and they act as a portal for infection. Ulceration, non-healing bruises and raised purple red nodules should lead to suspicion of malignancy.

Glomangioma (glomus tumor): Is an uncommon true benign tumor arising from contractile glomus cells that are present in the arterio venous shunts.

These lesions are found in the dermis of the fingers or toes under a nail and are extremely painful.

Arterio Venous Malformations: is a communication between an artery and vein without an intervening capillary. It may be congenital or acquired. It is clinically useful to identify three major groups ${ }^{4}$ of AVM's based on structural criteria. They are truncal, diffuse, and localized. Truncal fistula arise from major arterial branches. AVM's are most commonly found in the head and the neck, but trunk and extremity involvement is also seen. Diffuse AVMs are encountered particularly in the limbs and more frequently in lower than in upper limbs. These are recognizable by warmth, a palpable thrill and audible bruit. Traditional angiography or MRA to demonstrate their vascular anatomy is essential for confirming the diagnosis and developing a treatment plan.

\section{Hamartomas and Syndromes:}

1. Cowden syndrome is a serious genetic disorder characterized by multiple hemartomas usually of skin, but also of thyroid, G.I tract, Bones, CNS, Eyes and G.U tract. Cowden's syndrome is considered part of PTEN hemartomas tumor syndrome (PHTS) which also includes Bannyan Riley - Ruval caba syndrome, proteus syndrome, and proteus - like syndrome. 
2. Tuberous sclerosis ${ }^{2}$ is an autosomal dominant disease characterized by hemartomas of brain, retina, Pancreas, cardiac Rhabdomyomas, and mesenchymal tumors of kidney.

CONCLUSION: Though Hamartomas means fault and in Greek means missing the mark in spear throwing, the lesion misses to be malignant and maintains the benign nature. In our patient though initially it presented as lymph cyst. With HPE it turned to be a vascular Hamartomas which is not harmful for the patient.

\section{REFERENCES:}

1. Kevin G Burnand, Antony E Young, Jonathan Lucas et al. The New Aird's companion in surgical studies $3^{\text {rd }}$ ed, Elsevier, Churchill Livingstone.2005 P- 179 -81.

2. Emanual Rubin. Rubin Pathology Clinico Pathologic foundation of medicine. $4^{\text {th }}$ ed, Lippincott Willams and Williams; Philadelphia: 2005. P- 1491.

3. V. Krishan. Text book of Pathology, Orient Longman; Hyderabad, 2004 P - 479.

4. Josef E Fisher, Kirbay I Blard. Master of surgery, 5th ed: vol1. Wolter Kluwer; Lippincott Williams \& Wilkins. New Delhi.2008. P- 341-57.

5. Harsh Mohan. Text book of pathology, $6^{\text {th }}$ ed. Jaypee Brothers \& Publishers; New Delhi. 2010 P$411-13$.

6. J.C.E. Underwood, S.S. Cross. General and Systemic Pathology, 5ed Elevester Churchill Livingstone Edinburgh 2009. -

7. Norman S. Williams, Christopher J.K. Bulstrode, P. Ronnan O'Connell. International Students

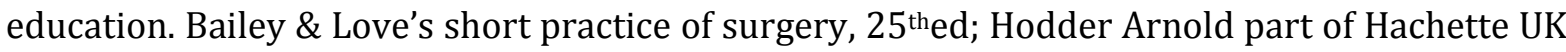
London 2008.P- 947-48.

8. Sunil Chumber. Essentials of Surgery. Jaypee Brothers\& Publishers New Delhi. 205 P-521

\section{AUTHORS:}

1. B. V. Sreedevi

2. A. Sasivannan

\section{PARTICULARS OF CONTRIBUTORS:}

1. Associate Professor, Department of Surgery, Tagore Medical College and Hospital, Rathina Mangalam.

2. Assistant Professor, Department of General Surgery, Tagore Medical College and Hospital, Rathina Mangalam.

\section{NAME ADDRESS EMAIL ID OF THE} CORRESPONDING AUTHOR:

Dr. B. V. Sreedevi, Associate Professor of Surgery, Rathina Mangalam, Kancheepuram.

E-mail: surgeonsreedevi@gmail.com

Date of Submission: 22/02/2014. Date of Peer Review: 23/02/2014. Date of Acceptance: 04/03/2014. Date of Publishing: 20/03/2014. 